\title{
Productivity and Profitability Estimates for Sonali Chicken Farms in Rajshahi, Bangladesh
}

\author{
M. S. Islam*, M. F. Hossen, M. M. Rahman \\ Genetics and Molecular Biology Lab, Department of Zoology, University of Rajshahi, Rajshahi \\ 6205, Bangladesh
}

Received 2 April 2021, accepted in final revised form 23 May 2021

\begin{abstract}
Season- and farm-wise productivity and mortality of Sonali chickens in 53 selected poultry farms from nine Upozillas of Rajshahi District during December 2018 and November 2019 were assessed. Results revealed that, on average, small farms produced 775, medium farms 1828 and large farms 3442 marketable live birds. Mortality was recorded in the following order: small farms > medium farms > large farms. Highest number of birds was produced in spring followed by winter, summer and rainy season, whereas the highest mortality was recorded in winter followed by rainy, summer and spring. Birds reared in smaller farms consumed greater amount of feed compared to those reared in larger farms. Consequently, the live weights, edible weights and edible ratios of the chickens differed significantly due to the farm size. Season-wise variations were significant for day-old chick price, gross return per bird and benefit-cost ratio. Farm-wise variations in the profitability components demonstrated that all the components of the large farms were significantly higher than those of the medium and small farms. With regard to the commercial poultry enterprise of the country, therefore, the present findings on Sonali chicken farming in Rajshahi District are quite encouraging from productivity, profitability and sustainability points of views.
\end{abstract}

Keywords: Productivity; Sonali chickens; Farm size; Benefit-cost ratio; Profitability.

(C) 2021 JSR Publications. ISSN: 2070-0237 (Print); 2070-0245 (Online). All rights reserved.

doi: http://dx.doi.org/10.3329/jsr.v13i3.52768 J. Sci. Res. 13 (3), 989-998 (2021)

\section{Introduction}

Productivity in terms of the number of live and marketable birds in meat producing, i.e., broiler commercial poultry enterprise, is usually associated with a number of factors such as farm size, bird age at selling, rearing seasons and mortality. Previous reports indicated that farm size greatly influences the productivity, profitability and sustainability of chicken farms [1-3]. Bird age, on the other hand, affects fecundity, fertility, hatchability, and hence the overall productivity of hens [4].

Poultry productivity is fluctuated by the rearing seasons because chickens are vulnerable to heat stress and they could only tolerate a narrow range of temperature. Hence, seasonal variation adversely affects the performance and health of broiler

\footnotetext{
${ }^{*}$ Corresponding author: saifulzoo.ru@gmail.com
} 
chickens, like poor feed conversion and low-quality chicks. Traits such as body weight, sexual maturity and egg shape index [5], growth performance including body weight, feed conversion ratio (FCR) and feed intake [6], operational and medication costs and day-old chick prices [7] and body weight, FCR and livability [8] have been associated with seasons for poultry chicken rearing.

Various data on the productivity of Sonali chickens (Gallus domesticus L.) in different regions of Bangladesh have been collected and reviewed by several researchers [9-15] and recently by NEA Report [16]. However, the overall productivity of poultry farms of the country is negatively affected by the mortality of chicks and adult birds due to bacterial, viral and fungal diseases [17-20], predators like wild cats, foxes, mongooses and human thieves [21,22], and occasional bird flu or avian influenza [23,24].

The profitability of a chicken species or breed like Sonali is vital to sustaining its commercial productivity in the country $[25,26]$. Previous workers have investigated and analyzed the profitability of several poultry birds including Sonali, Cobb 500, Fayoumi and RIR in various districts of Bangladesh [15,27-31], which suggest that Sonali has a satisfactory performance with the highest egg production, the lowest mortality and the highest profit per hen.

The aim of the present study was to investigate the effects of farm size, bird age and rearing seasons on the productivity and profitability of the crossbred Sonali chickens collected from 53 poultry farms scattered over nine Upozillas of Rajshahi District. The findings would help assess the feasibility and sustainability of the Sonali chicken farming in the study area.

\section{Materials and Methods}

\subsection{Study area}

Poultry farms from nine Upozillas (Police Stations) of Rajshahi District, viz., Bagha, Bagmara, Charghat, Durgapur, Godagari, Mohanpur, Paba, Puthia and Tanore (Fig. 1), that reared crossbred Sonali chickens [derived from Fayoumi hen $\times$ Rhode Island Red (RIR) cock], were selected for collecting experimental data for a period of one year from December 2018 to November 2019.

\subsection{Farm size}

A total of 53 poultry farms, consisting of five small ( $<1000$ birds), 27 medium (10002999 birds) and 21 large ( $\geq 3000$ birds), distributed throughout the aforesaid Upozillas were used for collecting relevant data on productivity and profitability components. 


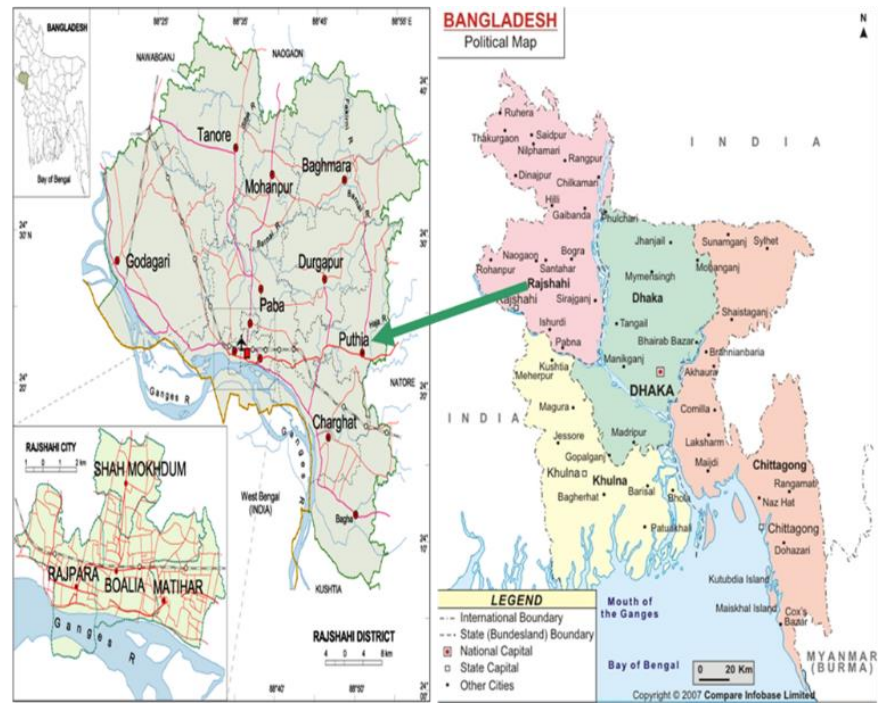

Fig. 1. Map of Bangladesh (right) showing Rajshahi District and Upozillas (left) under study (Source: www.google.com/earth).

\subsection{Rearing seasons}

Data for four arbitrary and overlapping rearing seasons of the fiscal year 2018-2019 and 2019-2020, namely, winter (Dec-Feb), summer (Mar-May), rainy (Jun-Aug) and spring (Sep-Nov) were used for the present study.

\subsection{Estimates of productivity and mortality}

The productivity of Sonali chicken farms in the study area was estimated by the number of marketable birds per farm per season. The number of dead birds per farm per season was recorded for estimating mortality (\%) per 100 day-old chicks (DOCs).

\subsection{Estimates of economic efficiency parameters (EEP)}

Such vital EEP as farm age (years), bird age at selling (days), food consumption (g) per bird per day (FCBD), live weight (LW in $\mathrm{g}$ ), edible weight ( $\mathrm{EW}$ in $\mathrm{g}$ ) and edible ratio (ER) that contribute substantially to the profitability of the farms under study were taken into account. All birds were fed ad libitum a commercial layer grower mash. The feed and water were supplied twice a day. Rice husk ( $8 \mathrm{~cm}$ thick) was used as a litter on the floor. Floor space per bird was approximately $500 \mathrm{~cm}^{2}$. For calculating LW, EW and ER, mean $\pm \mathrm{SE}$ values of 10 birds per farm were used as elaborated in previous reports [27,29]. 


\subsection{Estimates of benefit-cost ratio (BCR)}

For calculating BCR, data for DOC price, gross cost (GC) and gross return (GR) per bird were used as described in previous reports [10,15,32]. The GC included all expenditures for DOCs, feed, water, electricity, labor, disinfectants, antibiotics and vaccines. On the other hand, the GR included all income derived from selling excreta, eggs and live birds. Finally, BCR values per bird were calculated by using the formula: GR $\div$ GC for each farm size.

\subsection{Estimates of profitability components}

Components like average GC/flock/farm, GR/flock/farm and net profit (NP)/flock/farm were calculated for three farm sizes during the study period of one year. Farm-wise NP/flock was calculated by using the formula: GR/flock $\div$ GC/flock. Procedures described by earlier workers $[2,26,28]$ were followed.

\subsection{Statistical analyses}

Initially, descriptive statistics such as mean $\pm \mathrm{SE}$ and percentages were calculated for the collected raw data. Subsequently, the quantitative data for productivity and mortality, economic parameters, BCR and profitability components were subjected to one-way analysis of variation (ANOVA), where the levels of significance were set at $\mathrm{P}<0.05$, and the means were separated using Bonferroni's multiple comparison tests [33]. All experimental data were analyzed using SPSS for Windows (version 21.0).

\section{Results and Discussion}

\subsection{Productivity and mortality}

Effects of farm size on the productivity and mortality of Sonali chickens in selected poultry farms of Rajshahi District are presented in Table 1. Results revealed that, on average, small farms produced on average 775, medium farms 1828 and large farms 3442 marketable birds, where the farm-wise differences in productivity of Sonali chickens were significant $(\mathrm{P}<0.001)$. Differences in the number of dead birds between farm sizes were also highly significant $(\mathrm{P}<0.001)$, where the bigger farms resulted in increasingly greater number of dead birds in the following order: large farms $(344.93 \pm 28.07)>$ medium farms $(181.44 \pm 30.66)>$ small farms $(115.33 \pm 16.64)$. Conversely, mortality was higher in the smaller farms in the following order: small farms $(14.05 \pm 1.29)>$ medium farms $(8.79 \pm 1.55)>$ large farms $(5.87 \pm 1.19)$, differences being highly significant one ( $\mathrm{P}<$ $0.001)$. 
Table 1. Effects of farm size on the productivity and mortality of Sonali chickens in Rajshahi.

\begin{tabular}{llll}
\hline Farm size $^{1}$ & $\begin{array}{l}\text { No. birds produced } \\
(\text { Mean } \pm \text { SE) }\end{array}$ & $\begin{array}{l}\text { No. dead birds } \\
(\text { Mean } \pm \text { SE) }\end{array}$ & $\begin{array}{l}\text { Mortality (\%) } \\
(\text { Mean } \pm \text { SE) }\end{array}$ \\
\hline Small $(\mathrm{n}=5)$ & $775 \pm 116^{\mathrm{c}}$ & $115.33 \pm 16.64^{\mathrm{b}}$ & $14.05 \pm 1.29^{\mathrm{a}}$ \\
Medium $(\mathrm{n}=27)$ & $1828 \pm 604^{\mathrm{b}}$ & $181.44 \pm 30.66^{\mathrm{b}}$ & $8.79 \pm 1.55^{\mathrm{a}}$ \\
Large $(\mathrm{n}=21)$ & $3442 \pm 708^{\mathrm{a}}$ & $344.93 \pm 28.07^{\mathrm{a}}$ & $5.87 \pm 1.19^{\mathrm{b}}$ \\
F-values & $134.687(\mathrm{P}<0.001)$ & $9.263(\mathrm{P}<0.001)$ & $8.817(\mathrm{P}<0.001)$ \\
\hline
\end{tabular}

${ }^{1}$ Small farms $<1000$ birds, medium farms $=1000-2999$ birds, large farms $\geq 3000$ birds; Dissimilar superscripts differ significantly by Bonferroni's multiple comparison tests $(\mathrm{P}<0.05)$; Data for a period of one year from December 2018 to November 2019.

Effects of rearing seasons on the productivity and mortality of Sonali chickens in selected poultry farms of Rajshahi District are shown in Figs. 2a and 2b, respectively. Experimental data demonstrated that the highest number of birds was produced in spring (2670.00 \pm 322.91$)$ followed by winter $(2294.85 \pm 251.21)$ and summer $(1878.45 \pm 215.37)$, and the lowest number in the rainy season $(1675.65 \pm 228.94)$ in the study area, the differences in productivity were thus statistically significant one $(\mathrm{F}=2.948 ; \mathrm{P}<0.05)$. The number of dead birds was recorded in the following sequence: summer $(252.40 \pm 44.55)>$ winter $(215.82 \pm 78.39)>$ rainy $(185.44 \pm 33.91)>$ spring $(118.17 \pm 33.24)$, showing a significant difference between the seasons $(\mathrm{F}=2.849$; $\mathrm{P}<0.05)$. Season-wise difference in mortality was highly significant $(\mathrm{F}=3.891 ; \mathrm{P}<0.001)$, resulting in the highest mortality in winter $(14.05 \pm 2.09)$ followed by rainy $(10.15 \pm 2.10)$, summer $(9.13 \pm 1.29)$ and the lowest in spring $(4.35 \pm 1.49)$.
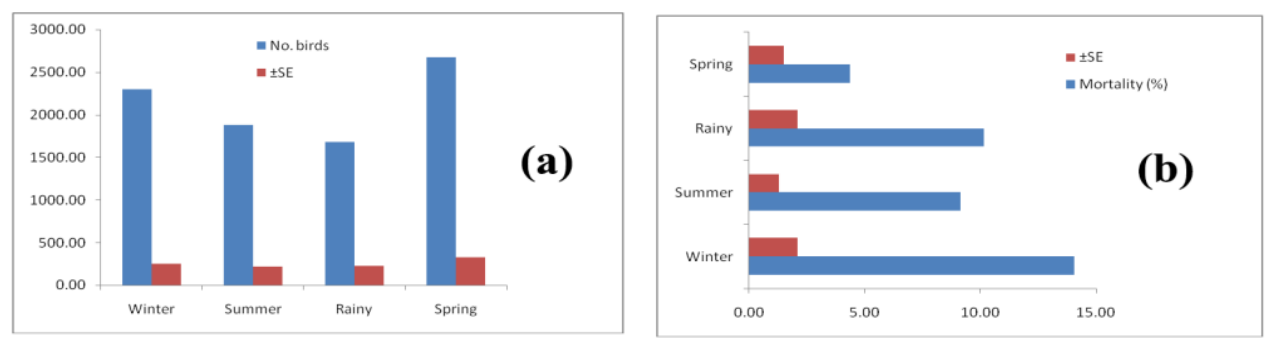

Fig. 2. (a) Season-wise mean \pm SE productivity of Sonali chickens in Rajshahi and (b) season-wise mean \pm SE mortality of Sonali chickens in Rajshahi.

\subsection{Economic efficiency parameters (EEP)}

Table 2 shows farm size-wise EEP such as farm age, bird age at selling, food consumption per bird per day (FCBD), live weight (LW), edible weight (EW) and edible ratio (ER) for Sonali chickens in the study area. Results indicated that the differences in farm age between the small, medium and large farms were significant $(\mathrm{F}=3.122 ; \mathrm{P}<0.05)$, but the selling age of the birds for the three farm sizes was not significant $(\mathrm{F}=1.891 ; \mathrm{P}>0.05)$. Farm-wise daily food consumption by the Sonali chickens was found to be highly significant $(\mathrm{F}=12.600 ; \mathrm{P}<0.001)$, where birds reared in smaller farms tended to consume a greater feed than those reared in larger farms. Consequently, the LWs, EWs and ERs of 
the experimental chickens differed highly significantly owing to the farm size $(\mathrm{F}=$ 213.388, $F=76.419$ and $F=8.609$, respectively; $P<0.001$ for all three), suggesting that small farms produced higher LW, increased EW but lower ER in comparison with the medium and large farms. Interestingly, the ER value was significantly higher for chickens from large farms than those from smaller farms, although the difference in ER between the medium and large farms was not statistically significant $(P>0.05)$.

Table 2. Effects of farm size and farm age on some economic efficiency parameters on Sonali chickens in Rajshahi.

\begin{tabular}{|c|c|c|c|c|c|c|}
\hline $\begin{array}{l}\text { Farm } \\
\text { size }^{1}\end{array}$ & $\begin{array}{l}\text { Farm age } \\
(\mathrm{yrs})\end{array}$ & $\begin{array}{l}\text { Bird age at } \\
\text { selling (d) }\end{array}$ & $\begin{array}{l}\text { FCBD } \\
(\mathrm{g})\end{array}$ & $\begin{array}{l}\text { Live wt (LW) } \\
(\mathrm{g})\end{array}$ & $\begin{array}{l}\text { Edible wt (EW) } \\
(\mathrm{g})\end{array}$ & $\begin{array}{l}\text { Edible ratio } \\
(\mathrm{ER})\end{array}$ \\
\hline Small (1 & $1.80 \pm 0.84^{\mathrm{c}}$ & $56.02 \pm 4.71^{\mathrm{a}}$ & $65.33 \pm 1.58^{\mathrm{a}}$ & $680.67 \pm 65.71^{a}$ & $380.40 \pm 23.11^{\mathrm{a}}$ & $0.55 \pm 0.08^{\mathrm{a}}$ \\
\hline Medil & 4.15 & $55.78 \pm 6.17^{\mathrm{a}}$ & $60.75 \pm 4.80^{b}$ & $7 \pm 47.91^{b}$ & $376.98 \pm$ & $0.58 \pm 0.11^{\mathrm{b}}$ \\
\hline Large & $5.76=$ & $56.34 \pm$ & $54.88 \pm 3.76^{c}$ & $\pm 50.02^{\mathrm{b}}$ & $374.43 \pm 18.43^{b}$ & $0.59 \pm 0.07^{\mathrm{b}}$ \\
\hline F-va & 3.12 & 1.891 & 12.600 & 213 & 76.415 & 8.609 \\
\hline (Probabilities) & $(\mathrm{P}<0.05)$ & $(\mathrm{P}>0.05)$ & $(\mathrm{P}<0.001)$ & $(\mathrm{P}<0.001)$ & $(\mathrm{P}<0.001)$ & $(\mathrm{P}<0.001)$ \\
\hline
\end{tabular}

${ }^{1}$ Small farms $<1000$ birds, medium farms $=1000-2999$ birds, large farms $\geq 3000$ birds; FCBD $=$ food consumption per bird per day; Dissimilar superscripts differ significantly by Bonferroni's multiple comparison tests $(\mathrm{P}<0.05)$; For LW, EW and ER values, mean \pm SE of 10 birds/farm were used.

\subsection{DOC prices, GC and GR per bird and BCR}

Season-wise variations in day-old chick (DOC) price, gross cost (GC) and gross return (GR) per bird and benefit-cost ratio (BCR) for Sonali chickens in the study area are presented in Table 3. Results showed a highly significant variation in DOC price ( $\mathrm{F}=$ 86.160; $\mathrm{P}<0.001)$ due to rearing seasons in the decreasing order of: summer (Tk.

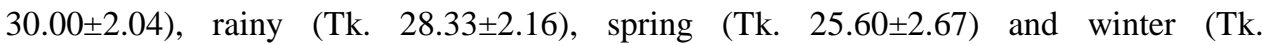
17.73 \pm 2.15$)$. Season-wise variations in the GR per bird $(\mathrm{F}=17.176 ; \mathrm{P}<0.001)$ and $\mathrm{BCR}$ $(\mathrm{F}=69.332 ; \mathrm{P}<0.001)$ were also significant, even though the GC per bird did not vary significantly throughout the seasons $(\mathrm{F}=2.555 ; \mathrm{P}>0.05)$. Thus, the highest and the lowest GC per bird were in summer (Tk. 101.53 \pm 2.01 ) and winter (Tk. 90.83 \pm 1.87 ), respectively, whereas the highest and the lowest GR per bird were in spring (Tk. 142.33 \pm 0.97 ) and winter (Tk. 109.37 \pm 1.98 ), respectively. Accordingly, the corresponding BCR values were the highest in spring $(1.51 \pm 0.09)$ and the lowest in winter $(1.21 \pm 0.23)$.

Table 3. Effects of seasonal variations on mean \pm SE DOC price, GC, GR and BCR of Sonali chickens in Rajshahi.

\begin{tabular}{llllc}
\hline $\begin{array}{l}\text { Rearing } \\
\text { seasons }\end{array}$ & $\begin{array}{l}\text { DOC price } \\
\text { (Tk.) }\end{array}$ & $\begin{array}{l}\text { GC per bird } \\
\text { (Tk.) }\end{array}$ & $\begin{array}{l}\text { GR per bird } \\
\text { (Tk.) }\end{array}$ & $\begin{array}{l}\text { Benefit-cost ratio } \\
\text { (BCR) per bird }\end{array}$ \\
\hline Winter & $17.73 \pm 2.15^{\mathrm{d}}$ & $90.83 \pm 1.87^{\mathrm{c}}$ & $109.37 \pm 1.98^{\mathrm{d}}$ & $1.21 \pm 0.23^{\mathrm{c}}$ \\
Summer & $30.00 \pm 2.04^{\mathrm{a}}$ & $101.53 \pm 2.01^{\mathrm{a}}$ & $134.00 \pm 0.87^{\mathrm{b}}$ & $1.32 \pm 0.07^{\mathrm{b}}$ \\
Rainy & $28.33 \pm 2.16^{\mathrm{b}}$ & $96.93 \pm 1.96^{\mathrm{b}}$ & $126.87 \pm 1.13^{\mathrm{c}}$ & $1.31 \pm 0.11^{\mathrm{b}}$ \\
Spring & $25.60 \pm 2.67^{\mathrm{c}}$ & $94.73 \pm 1.58^{\mathrm{b}}$ & $142.33 \pm 0.97^{\mathrm{a}}$ & $1.51 \pm 0.09^{\mathrm{a}}$ \\
F-values & $86.160(\mathrm{P}<0.001)$ & $2.555(\mathrm{P}>0.05)$ & $17.176(\mathrm{P}<0.001)$ & $69.332(\mathrm{P}<0.001)$ \\
\hline
\end{tabular}

DOC $=$ Day-old chick; GC $=$ Gross cost; GR $=$ Gross return; $\mathrm{BCR}=$ Benefit-cost ratio $(\mathrm{GR} \div \mathrm{GC})$; Dissimilar superscripts differ significantly by Bonferroni's multiple comparison tests $(\mathrm{P}<0.05)$. 


\subsection{Profitability components}

Farm-wise variations in the profitability components (Table 4) demonstrated that there exist highly significant differences for each component for Sonali chickens reared and marketed in Rajshahi. The GC per flock, GR per flock and NP per flock for small farms

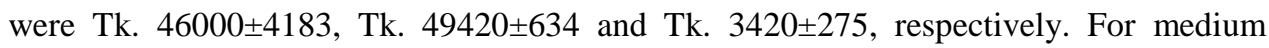
farms, the values were Tk. $132667 \pm 14827$, Tk. $145729 \pm 2052$ and $13059 \pm 1129$, respectively. For large farms, however, all the components had higher values of Tk. $357857 \pm 51266$, Tk. $397976 \pm 17324$ and $40119 \pm 3209$, respectively, suggesting that the overall GC $(\mathrm{F}=40.693 ; \mathrm{P}<0.001), \mathrm{GR}(\mathrm{F}=44.114 ; \mathrm{P}<0.001)$ and NP $(\mathrm{F}=10.420 ; \mathrm{P}<$ 0.01 ) of the large farms were significantly higher than those of the medium and small farms in the study area.

Table 4. Profitability components for Sonali chickens reared in various poultry farms in Rajshahi.

\begin{tabular}{llll}
\hline Farm size & GC per flock (Tk.) & GR per flock (Tk.) & NP per flock (Tk.) \\
\hline Small $(\mathrm{n}=5)$ & $46000 \pm 4183 \mathrm{c}$ & $49420 \pm 1634 \mathrm{c}$ & $3420 \pm 275 \mathrm{c}$ \\
Medium $(\mathrm{n}=27)$ & $132667 \pm 14827 \mathrm{~b}$ & $145729 \pm 2052 \mathrm{~b}$ & $13059 \pm 1129 \mathrm{~b}$ \\
Large $(\mathrm{n}=21)$ & $357857 \pm 51266 \mathrm{a}$ & $397976 \pm 17324 \mathrm{a}$ & $40119 \pm 3209 \mathrm{a}$ \\
F-values & $40.693(\mathrm{P}<0.001)$ & $44.114(\mathrm{P}<0.001)$ & $10.420(\mathrm{P}<0.01)$ \\
(Probabilities) & & & \\
\hline
\end{tabular}

${ }^{\text {I}}$ Small farms $<1000$ birds, medium farms $=1000-2999$ birds, large farms $\geq 3000$ birds; GC $=$ Gross cost; GR $=$ Gross return; NP $=$ Net profit; Dissimilar superscripts differ significantly by Bonferroni's multiple comparison tests $(\mathrm{P}<0.05)$.

Both productivity and profitability of poultry birds are found to be influenced by the farm or flock size and stocking density. Parameters like LW, FCR and cost per bird were higher for small flocks in comparison to those for the medium and large flocks, whereas net profit per flock was in the order of large flocks > medium flocks > small flocks [2]. Similarly, daily weight gain, economic performance and bird welfare were found to be positively associated with the flocking density [3]. These findings conform to our results, where small farms produced higher LW, increased EW but lower ER as compared to the medium and large farms.

In India, seasonal variables like temperature, relative humidity $(\mathrm{RH})$, rainfall, sunshine hours and rainy days play a significant role in body weight, sexual maturity and egg shape index of broiler poultry [5]. In Brazil, on the other hand, growth performance in terms of feed intake, FCR and body weight of broiler chickens were significantly higher in winter than summer, which resulted in increased production and profit per flock [6]. Likewise, the costs of DOCs, rearing, breeding and medication for poultry farms in Pakistan were also higher in winter than in summer, but the price of broiler was lower in summer compared to that in winter [7]. Winter was the best season for the small-scale broiler farmers to earn profitability in terms of FCR, LW and BCR in all the selected poultry farms in Assam, India [8]. These are in good agreement with ours because seasonwise variations in DOC price, GR and BCR per bird were significant between the three farm sizes in Rajshahi. 
In such Districts as Joypurhat, Mymensingh-Gazipur, Bogura and Naogaon of Bangladesh, Sonali chicken production in commercial farms has been increasing since 2010 [9-12], where Sonali performed better than other birds in terms of adaptability and BCR. In addition, people preferred Sonali chickens to indigenous birds. Moreover, Sonali DOCs represented about $35 \%$ of the commercial broiler and layer production throughout the country [14]. In a couple of recent studies, Sonali chickens were found to have relatively high meat content and have been the fastest-growing segment of poultry in Bangladesh $[15,16]$. These reports lend support to the present findings with regard to the farm- and season-wise productivity of Sonali chickens in the study area. The overall mortality of Sonali chickens was age-related and was found to have a wide range of variations as high as $53.33 \%$ [17] and as low as $3.8 \%$ [18] depending on the rearing seasons and regions of the country. Our data on mortality, the highest in winter $(14.05 \pm 2.09 \%)$ followed by rainy $(10.15 \pm 2.10 \%)$, summer $(9.13 \pm 1.29 \%)$ and the lowest in spring $(4.35 \pm 1.49 \%)$, however, did not agree with those reported by previous workers [17-20], perhaps due to the fact that Rajshahi District belongs to a different agro-climatic zone of Bangladesh.

Estimated GC, GR and net profit (NP) for 1000 broiler birds were at Tk. 99429, 109961 and 3631, respectively [26]. The highest BCR for Sonali was 1.11 followed by RIR and Fayoumi (1.10 each) and Cobb 500 (1.09) [27], whereas the average GC and GR for broilers per farm per year were Tk. 301142 and 431400, respectively. The broiler farming had a much higher BCR of 1.80 [28]. The average GC and GR values for 1000 Sonali chickens in Gazipur District were estimated at Tk. 120613 and Tk. 172672, respectively, where the calculated BCR was found to be 1.4 [10]. Again, Sonali intensive meat-producing breed had 1.49 BCR compared to commercial broiler (1.22) and commercial layer (1.11) farms, indicating that Sonali birds provide a profitable venture [15], in contrast, much higher BCR of 2.60 was estimated for a popular breed called Vanaraja in Assam, India [32].

The profitability index (PI) of government farms varied between -0.09 and -0.13 , while that in private farms ranged between 0.18 and 0.52 . Sonali was the most popular and cheapest breed compared to Fayoumi and RIR breeds [27]. NP of Tk. 27.58 \pm 2.40 , BCR of $1.25 \pm 0.02$ and profitability index (PI) of $0.20 \pm 0.01$ was estimated for Sonali chickens in the northern districts of Bangladesh [29]. Data from Brahmanbaria, Shariatpur and Sylhet districts showed that Sonali chicken rearing was a profitable enterprise as indicated by its higher BCR [30]. GC, GR, and profitability values for broiler production in Mymensingh district also revealed that poultry production was a profitable enterprise [31]. In Pakistan, the average profit of large broiler poultry farms was Rs. 85228 followed by medium (Rs. 58049) and small (Rs. 36090) farms [34]. Back in the country, data from commercial poultry farms in Mymensingh district showed the following profitability analysis: average GC and GR per farm per year were Tk. 217355 and Tk. 393106, respectively, where the BCR per farm per year was 1.55 [15]. In the present study, the average GC per flock of Tk. 46000, Tk. 132667 and Tk. 357857 were estimated for small, medium and large farms, respectively. Moreover, average GR per flock of Tk. 49420, Tk. 
145729 and Tk. 397976, and the average NP per flock of Tk. 3420, Tk. 13059 and Tk. 40119 , respectively for the three farm sizes have been assessed. The apparent differences between our findings and those of the aforesaid reports might have resulted due to the variations in stocking density, rearing seasons and farm management practices.

\section{Conclusion}

Our current findings on the farm- and season-wise productivity and profitability components of the existing Sonali chicken farms situated in nine different Upozillas of Rajshahi District have demonstrated clearly that Sonali farming is a profitable enterprise in the study area, which is quite encouraging in terms of productivity, profitability and sustainability of the Sonali poultry farms in the country as a whole.

\section{Acknowledgments}

Sincere co-operation and assistance received from Sonali poultry farm owners and workers of the study area are thankfully acknowledged. We are grateful to the Chairman, Department of Zoology, University of Rajshahi, for providing laboratory facilities, and to T. Sultan, Laboratory Attendant, for his technical assistance.

\section{References}

1. P. H. Zimmerman, A. C. Lindberg, S. J. Pope, E. Glen, J. E. Bolhuis, and C. J. Nicol, Appl. Anim. Behav. Sci. 101, 111 (2006). https://doi.org/10.1016/j.applanim.2006.01.005

2. A. S. S. El-Tahawy, A. E. Taha, and S. A. Adel, Eur. Poult. Sci. 81 (2017). https://doi.org/10.1399/eps.2017.175

3. S. Bergeron, E. Pouliot, and M. Doyon, Animals 10, 1253 (2000). https://doi.org/10.3390/ani10081253

4. Y. I. Zabudskii, Agric. Biol. 51, 436 (2006). https://doi.org/10.15389/agrobiology.2016.4.436eng

5. G. D. Nayak, N. C. Behura, K. K. Sardar, and P. K. Mishra, Vet. World 8, 472 (2015). https://doi.org/10.14202/vetworld.2015.472-477

$6 . \quad$ R. I. Osti, D. I. I. Bhattarai, and D. I. Zhou, Brazilian J. Poult. Sci. 19, 489 (2017). https://doi.org/10.1590/1806-9061-2017-0494

7. M. Naeem and M. Khan, Sarhad J. Agric. 35, 408 (2019). https://doi.org/10.17582/journal.sja/2019/35.2.408.416

8. M. Sarma, M. K. Borah, K. P. Kalita, J. D. Mahanta, N. Kalita, J. K. Talukdar, P. Deka, T. K. Amonge, and R. Islam, Int. J. Livestock Res. 9, 246 (2019). https://doi.org/10.5455/ijlr.20181029040524

9. K. S. Huque, M. A. Saleque, and R. Khatun, Commercial Poultry Production in Bangladesh, Bangladesh Livestock Research Institute (BLRI) (Savar, Dhaka, Bangladesh, 2012).

10. M. T. Uddin, S. J. Mitu, and I. A. Begum, Bang. J. Anim. Sci. 43, 56 (2014). https://doi.org/10.3329/bjas.v43i1.19386

11. FAO, Animal Production and Health Working Paper No. 14. (Rome, Italy, 2015).

12. A. Mitchell, (2015). https://thepoultrysite.com/articles/can-the-sonali-chicken-crossbreedimprove-the-poultry-industry-in-bangladesh

13. M. Shahjahan and A. K. F. H. Bhuiyan, Asian Australas. J. Biosci. Biotechnol. 1, 557 (2016).

14. SAC (SAARC Agriculture Centre) Report (2017). 
15. M. Modak, E. H. Chowdhury, M. S. Rahman, and M. N. Sattar, J. Bangladesh Agril. Univ. 17, 50 (2019). https://doi.org/10.3329/jbau.v17i1.40663

16. NEA (Netherlands Enterprise Agency) Report (2020). NEA reference: PST19BD01.

17. S. M. S. H. Belal, Bangl. J. Vet. Med. 15, 107 (2017). https://doi.org/10.3329/bjvm.v15i2.35519

18. M. A. Rouf, M. S. Hossain, M. M. Hasan, M. R. Nabi, M. M. Rahman, and S. M. H. Rashid, Int. J. Appl. Res. 3, 13 (2017).

19. M. L. Talukdar, F. T. Zuhra, K. M. E. Islam, and M. S. Ahmed, J. Adv. Vet. Anim. Res. 4, 39 (2017). https://doi.org/10.5455/javar.2017.d188

20. M. Al Mamun, K. M. Islam, and M. M. Rahman, MOJ Proteomics Bioinform. 8, 7 (2019).

21. P. K. Biswas, G. M. N. Uddin, H. Barua, K. Roy, D. Biswas, A. Ahad, and N. C. Debnath, Prev. Vet. Med. 76, 185 (2006). https://doi.org/10.1016/j.prevetmed.2006.05.001

22. O. F. Miazi, G. Miah, M. M. Hasan, M. M. Uddin, M. E. Hossain, M. S. Mahmud, and M. F. Ahsan, Int. J. Rec. Res. Life Sci. 2, 1 (2015).

23. S. K. Raha, in Proceedings of the $8^{\text {th }}$ Int. Poultry Show and Seminar 2013.World's Poultry Science Association, Bangladesh Branch (2013) pp. 13-19.

24. N. Moyen, G. Ahmed, S. Gupta, T. Tenzin, R. Khan, T. Khan, N. Debnath, M. Yamage, D. U. Pfeiffer, and G. Fournie, BMC Vet. Res. 14, 12 (2018). https://doi.org/10.1186/s12917-018-1331-5

25. M. Rahman, P. Sorensen, H. A. Jensen, and F. Dolberg, Livestock Res. Rural Dev. 9 (3) (1997).

26. S. Akhter, M. H. A. Rashid, and H. Uddin, Progress. Agric. 20, 231 (2009). https://doi.org/10.3329/pa.v20i1-2.16875

27. M. S. Islam, M. A. Kabir, and R. K. Dutta, J. Life Earth Sci. 7, 21 (2012). https://doi.org/10.3329/jles.v7i0.20117

28. A. Akter, MS Thesis, Sher-e-Bangla Agricultural University, Dhaka, Bangladesh (2013).

29. M. S. Islam and R. K. Dutta, Int. J. Sci. Res. Environ. Sci. 2, 174 (2014).

30. M. C. Sumy, M. K. I. Khan, and M. M. Islam, Livestock Res. Rural Dev. 26 (2014).

31. M. S. R. Chowdhury and M. M. Chowdhury, Dev. Country Stud. 5, 107 (2015).

32. R. Islam, P. Nath, A. Bharali, and R. Borah, J. Res. Agric. Anim. Sci. 3, 7 (2015).

33. J. H. Zar, Biostatistical Analysis, $5^{\text {th }}$ Edition (Pearson, India, 2009) pp. 756.

34. M. Khan and M. Afzal, Sarhad J. Agric. 34, 389 (2018). https://doi.org/10.17582/journal.sja/2018/34.2.389.394 